\title{
THE IMPORTANCE OF IMPROVING LEXICAL COMPETENCE OF MEDICAL STUDENTS IN TEACHING ENGLISH AS A FOREIGN LANGUAGE
}

\author{
Nazarova Mukaddas Yuldashbaevna \\ Assistant Teacher, \\ Department of Foreign, \\ Latin Languages, and Medical Terminology, \\ Karakalpakstan Medical Institute, \\ Nukus, Uzbekistan, \\ Karakalpakstan
}

Article DOI: https://doi.org/10.36713/epra5787

\begin{abstract}
The article describes the importance of the lexicon component in teaching medical terms for English for specific purposes (ESP) students who study medicine. It deals with some problems in the process of teaching English as a foreign language (EFL) for medical students. This article discusses the methodology of teaching EFL effectively in the Karakalpak classroom. The present paper traces the evolvement of the significance of vocabulary in foreign language learning, and offers a look at several approaches, related to foreign language vocabulary knowledge development, that can be included as part of our classroom practices for the benefit of our learners. As a result of discussion and analysis we concluded that it is pivotal to make use of different methods in the process of teaching EFL for ESP students.

KEY WORDS: English as a foreign language (EFL), English for specific purposes (ESP), medical terminology, teaching, learning, medicine.
\end{abstract}

\section{INTRODUCTION}

In Karakalpakstan students before entering higher educational institutions acquire foreign languages at schools and secondary special educations, and they carry on studying English as a foreign language as well as major to gain language competence to be able to proceed with their professional career in the future. There is no doubt that foreign language teaching and learning has evolved over many years, distinguishing varied trends in the course of its history.

Furthermore, vocabulary has been the dominant focus in the last decades despite it being an undervalued and often overlooked component in the earlier stages. We have become aware of a general consensus among teachers that lexical development plays an essential role in mastering a foreign language. Apart from classroom practices and educational policies governing a foreign language, the crucial role that vocabulary plays in language competence has been more acknowledged in language acquisition research. In fact, language learners themselves consider vocabulary knowledge to be of primary importance and believe that their difficulties in both receptive and productive language use stem from inadequate vocabulary knowledge, evaluate and apply currently available strategies to encourage vocabulary development.

To understand what lexical competence is, it is essential to try to understand what it means to know a word. Richards (2002) was one of the first applied linguists to propose the concept of "knowing a word" which, in his opinion, included knowing the degree of probability of encountering a word in speech or print, the limitations on the use of the word according to variations of function and situation, the syntactic behavior associated with the word, the underlying form of the word and the derivations that can be made from it, the network of associations between the word and other words in the language, the semantic value of the word, and the different meanings associated with the word. Largely retaining this lexical knowledge framework of Richards, Nation (1990) added pronunciation as an important component to make the framework more inclusive. In addition, Nation (1990) made explicit the distinction between the receptive and productive knowledge of vocabulary, pointing out that production involved a 
higher level of knowledge of vocabulary than reception did. Later, Nation (2001) revised his early framework to point out that the knowledge of a word or, in other words, lexical competence, includes three kinds of knowledge:

1. Knowledge of form (spoken form, written form and word parts);

2. Knowledge of meaning (form and meaning, concept and referents, and associations);

3. Knowledge of use (grammatical functions, collocations and constraints on use).

As Dik (1997, p.5, 6) claims that the psychological correlate of a natural language is the notion of communicative competence as introduced by Hymes (1972). He points out that communicative competence comprises "not only the ability to construe and interpret linguistic expressions, but also the ability to use these expressions in appropriate and effective ways according to the conventions of verbal interaction prevailing in a linguistic community". It may seem natural to suppose that lexical competence, which could accordingly be defined as the ability to use words in appropriate and effective ways in verbal interaction, is part of communicative competence as defined above. However, in current linguistic theory there has been an unfortunate tendency to concentrate on the meticulous analysis of lexical meaning in order to account for the structural properties of lexical items, while ignoring significant aspects of the use and behaviour of lexemes in linguistic utterances.

\section{OBJECTIVES}

Currently, it is widely accepted that the English language has become the language of international communication. Careful examination of the attitudes and perceptions of learners and instructors is seen to be important in determining the problems of ESP courses. Acquisition of a foreign language is often viewed as a process that differs from native-language acquisition, and it is frequently assumed that factors influencing

one's ability to acquire a second language do not play a role in native language development).

Although the medical institution curriculum is taught in the Karakalpak, Uzbek and Russian languages, all first year students, regardless of their language proficiency level, receive an intensive course in English along with their other premedical requirements. When they start the courses they might face with increased academic demands at the beginning and quickly realize that they need to develop appropriate learning skills. It has been noticed that medical students in EFL context are most likely facing problems in dealing with their medical subjects and that can be attributed partially to the English Language barrier. Cleary the English language used in such a context includes special terms and linguistic structures the students have never encountered before.

\section{METHODOLOGY}

According to Rieder (2003), incidental vocabulary learning occurs through the process of inferring word meanings when the learner encounters unknown or unfamiliar words when engaging in tasks such as reading. Extensive reading (ER) essentially independent reading, broadly and in quantity over a continual period of time - is one of the primary means of learning vocabulary. The method has proven to be successful in not only improving vocabulary and grammatical knowledge, but has also managed to develop positive attitudes towards foreign language reading among learners of all levels. According to Day and Bamford (1998), among the leading proponents of ER, outlined the following ten criteria found in successful ER programmes:

a) Reading as much as possible;

b) A variety of materials on different topics is available;

c) Reading materials are well within the linguistic competence of the students;

d) Selecting materials to read;

e) Reading for pleasure, information and general understanding;

f) Reading is individual and silent;

g) The reading rate or speed is usually faster;

h) Reading is its own reward (post-reading activities are discouraged);

i) The teacher is a role model of a reader, an active member of the classroom reading community;

j) Students are oriented to the programme's goals, given guidance, and their progress tracked.

Teachers might elect to complement their reading programme with post-reading activities (vocabulary worksheets) if they prefer applying an approach that covers both incidental and intentional vocabulary learning. Language learners in general actually stand to reap a lot of benefits from intentional vocabulary learning which, according to Ellis (2005, 1999), involves the purposeful learning of lexical information through activities such as direct vocabulary study. Isolating words from their contexts and studying them ensures not only that the correct meaning is learnt, but also heightens the potential for the words to be reinforced and as a result, to be better retained. Rosszell (2007, p. 59) pointed out that decontextualised word study in fact "acts as a buttress against the potentially inefficient or faulty learning outcomes that can result from an overreliance on a strategy of inferring word meanings from context".

Accordingly, there are two approaches to intentional vocabulary learning: the teacher/classroom-centred approach and the 
independent approach. However, it is important to pay attention that both approaches can be effective and the realisation that they can only be effective if we go beyond mere memorisation. In order to promote better knowledge retention, it is vitally important to elaborate cognitive processing takes place during learning (Tan, Pandian, Jaganathan, 2015). Currently, the question is no longer "Should we focus on vocabulary?" but rather "How do we get students to learn vocabulary effectively?". The central importance of vocabulary knowledge in language acquisition first, second or foreign is obvious, and having control over both the receptive and productive measures is indispensable. It is noteworthy that although many vocabulary teaching and learning strategies have been made available to us, it is pertinent for us to constantly gauge their suitability, adapt them to the immediate needs of our learners, evaluate their effectiveness and most importantly, improve upon them.

\section{RESULTS}

When we look at some literature, the teaching of medical terminology, with structural analysis of the term forming elements such prefixes and suffixes (Boztas, 1988; Erten 2001;

Laar, 1998), and teaching technical terminology as well as less specialized technical vocabulary in the context of case histories and problem-based tasks (Kimball, 1998;

Wood and Head, 2004) have been discussed. As well as medical terminology, some researcher have tried to analyze the linguistic structures mainly used in doctor-patient communication and conferences.

However, translation could still be useful to understand very complex sentences, so we suggest situational translation, instead of translating all the words and sentences in the passage. For the situations in which they feel in great difficulty, for example, understanding very long sentences with complex grammar structures, translation might be necessary for them. The grammar translation method has been widely used in EFL teaching worldwide. However, it should be borne in mind that translation of medical texts has its own problems and may not be much more effective as it can result in dependence on the practice of translation itself, which is very time consuming for the students.

Thus, in order to fully meet the wants and desires in terms of translation in teaching, the teachers at the Medical Institution should be familiar with the translation techniques and translations of the medical texts, but should certainly not rely on it fully. The students should be given more problem-oriented tasks which will reflect their cognitive ability and their own academic skills. Academicians who are familiar with the benefits of PBL (Problem Base Learning strategy) agree that it can be adapted to use in English for medical purposes classes. The aim of PBL is to enable students to understand related content knowledge and to develop the meta-cognitive skills which will make them good learners and problem solvers (Harland, 2003). Harland states that facilitating learning in PBL groups is different from the traditional teachers' role, and teaching becomes more like research, supervision and mentoring. Teachers monitor the students with suggestions for further study or inquiry but do not assign predetermined learning activities. Instead, students can develop appropriate questions, and produce their own solution to a problem. The necessary grammar or vocabulary items are acquired during the implementation of the tasks.

Also, learners acquire good knowledge during their research and can easily integrate it into their existing knowledge. According to the literature, PBL is an effective method in that it not only improves medical students' clinical skills but also their selflearning skills, making them more autonomous learners of health care issues. Using PBL in their English classes can also be beneficial to help the students adapt more easily to the PBL approach when they face it in their medical classes.

\section{DISCUSSION}

The language of medicine is a kind of literary language serving professional fields and the subject of a special study of the medical students focused on the acquisition of language as a means of professional communication. By an old tradition the language of medicine represents the combination of Latin and English terms being the means of international communication and the basis of studying medical disciplines. The education of qualified medical professionals presupposes teaching fundamental elements as well as modern medical terminology and vocabulary. The course of education meets not only informative, but also, communicational needs of the medical students, promoting the formation of communicative and socio-cultural competence.

Communicative competence serves for the purpose of improvement of professional competence and broadens the framework of students' professional behavior. The majority of medical and paramedical terms make up modern medical terminology. Each term is an element of subsystems, such as anatomical, histological and embryological, medical, surgical, gynecological, endocrinological, forensic, trauma, mental health, genetic, botanical, biochemical terms interact and correlate with each other in course of medical education and professional practice. Reading and translating Latin and English texts fosters language skills and forms professional speech patterns in future nurses, obstetricians and medical assistants. 
At the initial stage of English, medical students learn the language of everyday communication, which does not provide acquisition of the language used in the special areas of communication. Students learn basic communication patterns and main rules of international and home speech etiquette what helps them to improve their own communication skills and follow the established norms of communication. Basic speech skills are important in case of professional communication. In a medical practice it is vital to be able to speak with patients and engage them in communication. Sometimes a little chat with a patient helps more than a pill. In our institution, medical students study various basic topics including: Description of the character and personality, Healthy lifestyle, social life and media, climate and environmental problems and their influence on people, Educational and culture topics, scientific issues.

Also, it is pivotal to teach students not only to know medical terminology but also to comprehend it. The proper use of the language may also facilitate the adaptation of foreign health professionals to a new social or working environment. The study of medical terminology may become one of the mechanisms to overcome problems occurring in the course of professional communication.

\section{CONCLUSION}

As we are aware of that the International medical language is Latin. All terminology in use in Anatomy, Biology, Zoology, Microbiology, Pharmacology, Pharmacognosy, Pharmacy, Chemistry and other medical disciplines is in Latin. Because English language has the same Latin roots for its terminology the students tend to think that this is English. The real practice is that the pronunciation of the terminology in English is according to the normal rules for reading. There are often exceptions where in the pronunciation of the terminology Latin principles of reading (and in some cases the Greek one, whether the root originates from Greek) are followed. It should be taken into account that in the Medical Institution students take exams on other subjects, but not oral English.

In this case, it is quite possible that the same technique will provide different results in different classes. Students learn advanced medical vocabulary and read authentic scientific articles. In the process of professionalization of foreign language the integration of medical disciplines deepens students' medical knowledge and prompts scientific research. Merging of professional and language knowledge systems, as well as their associated professional and linguistic skills enables students to enhance their professional abilities in practical training or in the hospital. Thus, the medical students have probably the hardest task because they should obtain knowledge in English Medical Terminology.

\section{REFERENCES}

1. Alptekin, C. 2002. Towards intercultural communicative competence in ELT. ELT Journal $56(1): 57-64$.

2. Boztas, I. 1988. Identifying academic English needs of English-medium medical students Education for Health 22 (2).

3. Boztas, 1988 Erten 2001; Laar, 1998), specialized technical vocabulary in the context of case histories and problem- based tasks (Kimball, 1998; Wood \& Head, 2004).

4. Dik, S.C. Stepwise lexical decomposition. Lisse: The Peter de Ridder Press, 1978.

5. Day, R.R., \& Bamford, J. (1998). Extensive reading in the second language classroom. Cambridge, UK: Cambridge University Press.

6. Ellis, N.C. (2005). At the interface: Dynamic interactions of explicit and implicit language knowledge. Studies in Second Language Acquisition, 27, 305-352.

7. Hymes, D. On communicative competence. In: PRIDE, J. B., HOLMES, J. Sociolinguistics. Harmondsworth: Penguin, 1972. p.269-293.

8. Marconi, D. Lexical competence. Cambridge: MIT Press, 1997.

9. Nation, I.S.P. (1990). Teaching and learning vocabulary. New York: Newbury House.

10. Nation, I.S.P. (2001). Learning vocabulary in another language. Cambridge: Cambridge University Press.

11. Richards, J. C., Renandya, W. A. (Eds.). (2002). Methodology in language teaching: An anthology of current research. New York: Cambridge University Press.

12. Rieder, A. (2003). Implicit and explicit learning in incidental vocabulary acquisition. VIEWS, 12(2), 24-39.

13. Rosszell, H.R. (2007). Extensive reading and intensive vocabulary study in a Japanese university. (Unpublished doctoral thesis). Temple University, Japan.

14. Tan, D.A.L., Pandian, A., \& Jaganathan, P. (2015). Reading for lexical development: Depth of processing and the systematic selection of comprehensible input. International Journal of Educational Research, 3(7), 109-120. 